\title{
Dipsacussaponin C from Dipsacus asper Reduces the Risk of Gastritis and Gastric Ulcer in Rats
}

\author{
Seon A Hwang ${ }^{1}$, In Young Hwang ${ }^{1}$, Joohee Jung ${ }^{1}$, Hye Kyung Kang ${ }^{1}$, Kun Ho Son ${ }^{2}$, \\ Choon Sik Jeong ${ }^{1^{*}}$ \\ ${ }^{1}$ College of Pharmacy, Duksung Women's University, Seoul, South Korea; ${ }^{2}$ Department of Food Science and Nutrition, Andong \\ National University, Gyeongbuk, South Korea. \\ Email: ${ }^{*}$ choonsik@duksung.ac.kr
}

Received April $3^{\text {rd }}, 2012$; revised June $11^{\text {th }}, 2012$; accepted June $18^{\text {th }}, 2012$

\begin{abstract}
The roots of Dipsacus asper (DA) have been used as a tonic and analgesic agent in traditional Chinese medicine for the treatment of osteoporosis, low back pain, knee pain, and as an anti-inflammatory agent. Few studies have reported pharmacological gastric activities. In this study, we investigated the effects of dipsacussaponin C (DSC) and 70\% ethanol and water extracts of DA on gastritis and gastric ulcer in rat. First, we examined the free radical scavenging effect by the 2,2-Diphenyl-1-picrylhydrazyl (DPPH) radical-scavenging assay. Second, we examined the Helicobacter pylori (H. pylori) colonization inhibitory effect and found that DSC has a mild anti-H. pylori effect. Third, the cytotoxicity was assessed by measuring the cell viability of human gastric cancer cells (SNU638 and AGS). Also, we observed the acid-neutralizing capacity by measuring $\mathrm{NaOH}$ consumption volume and found that DSC is effective as an antacid agent. For these reasons, we observed the effect of DSC on HCl-ethanol-induced gastritis and indomethacin-induced gastric ulcer in rat. In pylorus-ligated rats, DSC $(200 \mathrm{mg} / \mathrm{kg})$ also decreased the volume of gastric secretion (approximately $2.2 \mathrm{~mL})$ and gastric acid output $(0.16 \mathrm{mEq} / 4 \mathrm{hrs})$. From these results, we suggest that DSC isolated from DA may be useful for the treatment and/or protection of gastritis and gastric ulcer.
\end{abstract}

Keywords: Dipsacussaponin C; Dipsacus asper; Antioxidants; Gastritis; Gastric Ulcer

\section{Introduction}

Dipsaci Radix, the roots of Dipsacus asper. (Dipsacaceae) [1] have been used as a tonic, an analgesic and an antiinflammatory agent in traditional Chinese medicine to treat spermatorrhea, pain and fracture [2]. Phenolic acids, iridoid glycosides loganin, cantleyoside, triplostoside A, lisianthioside, sweroside, as well as triterpenoidsoleanic acid and akebiasaponin $\mathrm{D}$ and dipsanosides $\mathrm{C}$ have been identified from the root of DA [3]. Recently, pharmacological studies demonstrated that DA and isolated constituents from DA have many biological activities.

In a previous study, the protective properties of DA extract reduced the cognitive deficits and overexpression of $\beta$-amyloid protein induced by aluminum exposure. DA extract also suppressed aluminum-induced overexpression of hippocampal A $\beta$ immunoreactivity [4].

The seven hederageninsaponins isolated from the root of DA were investigated in vitro against tumor cell lines and showed cytotoxicity and cytotoxic potency [5]. Asperosaponin VI isolated from DA provides significant cardioprotective effects against acute myocardial infarc-

"Corresponding author. tion in rats. The mechanisms might involve scavenging lipid peroxidation products and reactive oxygen species, increasing antioxidant defense enzymes and preventing mitochondrial damage [6]. Akebiasaponin D from the roots of DA exerted strong cytotoxicity against human and murine leukemia cells. This anti-carcinogenic activity occurred via induction of apoptosis through activation of nitric oxide and apoptosis-related p53 and Bax gene expression [7]. Dicaffeoylquinic acid derivatives isolated from DA had antioxidant activities and inhibited LDL oxidation mediated by $\mathrm{Cu}^{2+}$ ions to prevent the development and progression of atherosclerotic disease [8]. In another previous study, DSC (Figure 1) showed an antinociceptive effect when it was administered spinally, and $\mathrm{GABA}_{\mathrm{A}}, \mathrm{GABA}_{\mathrm{B}}, \alpha_{2}$-adrenergic and serotonin receptors located at the spinal cord level, but not opioid receptors, may be involved in DSC-induced antinociception [9]. However, to date, few studies on the gastric effects of DA have been carried out.

In a previous study, DA extract may have antioxidant effects, and Dipsacussaponins have been identified to be the most abundant bioactive constituent in the root of DA 


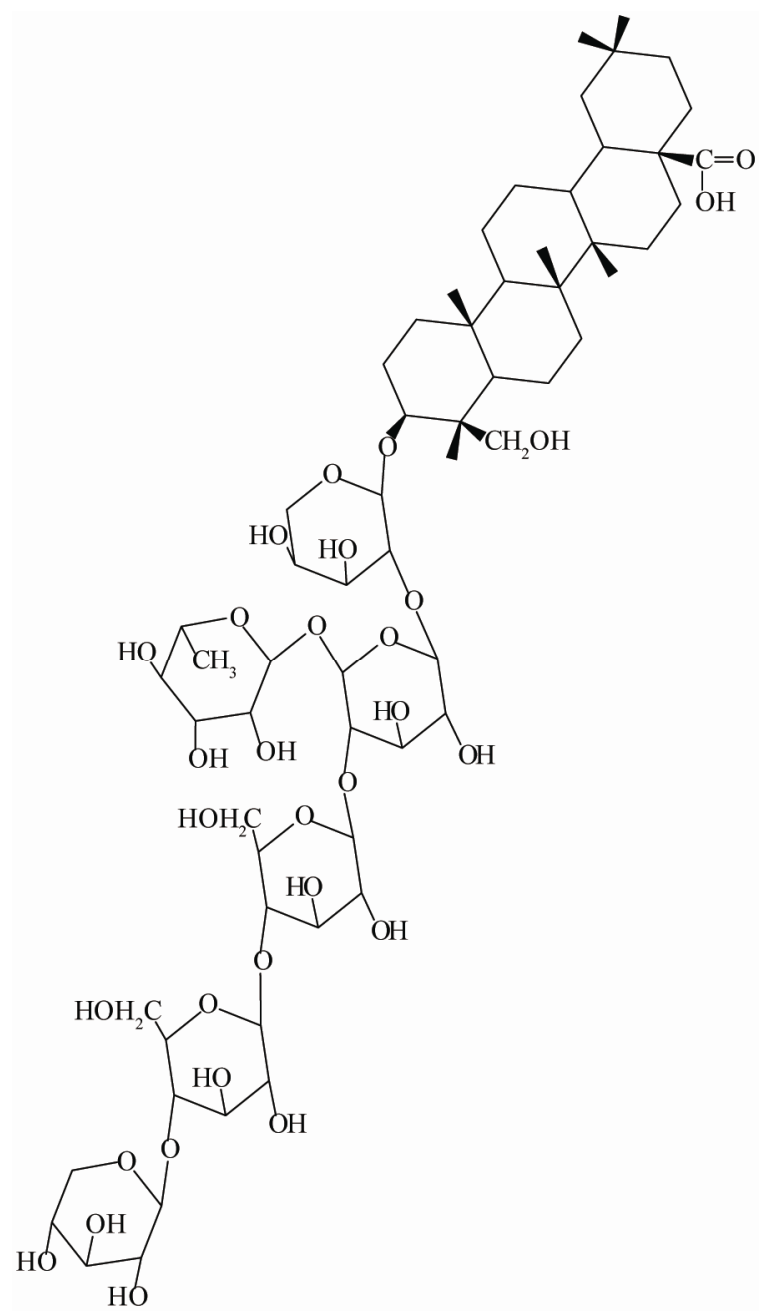

Figure 1. Structure of dipsacussaponin C.

[4]. Scientists have demonstrated that reactive oxygen species (ROS) such as superoxide anions $\left(\mathrm{O}_{2}^{-}\right)$, hydrogen peroxide $\left(\mathrm{H}_{2} \mathrm{O}_{2}\right)$, and hydroxyl radicals $(\cdot \mathrm{OH})$ were the major causative factors for stress-induced gastric ulceration. Resulting oxidative stress is crucially responsible for the development and progression of epithelial necrosis and mucosal ulceration [10]. In our study, we focused on gastritis and gastric ulcers protective effect of DA.

Gastritis and gastric ulcer can be induced by several factors, including stress, smoking, nutritional deficiencies, and nonsteroidal anti-inflammatory drugs (NSAIDs) [11]. Gastritis and gastric ulcer, like many other tissue damages, are mediated through generation of superoxide anions, $\mathrm{O}_{2}^{-}$, and its in situ interaction between protective and aggressive factors [12].

Infection with $H$. pylori is the strongest recognized risk factor for gastric cancer. This progression is probably multifactorial, being influenced by genetic or environmental factors in addition to $H$. pylori infection [13].
H. pylori induce chronic gastritis in virtually all infected subjects. This inflammation can lead to peptic ulceration and atrophic gastritis in a considerable number of infected subjects. A minority eventually develops gastric cancer [14]. The pathogenesis of peptic ulcer and gastric cancer is closely associated with $H$. pylori infection and its subsequent gastritis. H. pylori-induced gastritis is an important risk factor in the multifactorial etiology of these diseases [15].

There have been widespread reductions in gastric cancer incidence and mortality around the world in the last 50 years. Nonetheless, gastric cancer is still estimated to account for about $10 \%$ of invasive cancers worldwide (excluding nonmelanocytic skin cancers) and is probably the second leading cause of cancer death [16].

Therefore, the aim of this study was to investigate the anti-gastritis, anti-gastric ulcer and anti-gastric cancer cell growth effects of DSC by measuring the anti-oxidant activities, colonization and $H$. pylori growth, cytotoxicity to gastric cancer cells, and gastric secretion. We also investigated the effects of DSC on gastritis and gastric ulcer in rats.

\section{Materials and Methods}

\subsection{Materials}

The roots of DA were purchased from Herbal Medicinal Materials Company of Yak-Ryong-Si Province (Daegu, South Korea), and authenticated by Prof. J.-H. Lee (College of Oriental Medicine, Dongguk University, Gyeongju, Republic of Korea). DSC was isolated from the $\mathrm{MeOH}$ extract of the roots of DA and its structure was confirmed by comparison with the literature [17]. The dried roots of DA $(19.6 \mathrm{~kg})$ were refluxed with hot $\mathrm{MeOH}$ (3 times) and concentrated to give a residue (3854.91 g) that was subsequently suspended in $\mathrm{H}_{2} \mathrm{O}$ and partitioned with hexane $(62.65 \mathrm{~g}), \mathrm{CH}_{2} \mathrm{Cl}_{2}$ (227.84 g), EtOAc $(180.91 \mathrm{~g})$ and $\mathrm{BuOH}(881.27 \mathrm{~g})$. The $\mathrm{BuOH}$ extract $(150 \mathrm{~g})$ was loaded on a silica gel column $(80 \mathrm{~cm}$ $\times 15 \mathrm{~cm})$ and eluted with a gradient of $\mathrm{CH}_{2} \mathrm{Cl}_{2} / \mathrm{MeOH}$ $(100: 0,95: 5,93: 7,90: 10,0: 100)$ to give 16 fractions. Fraction 12 (2.33 g) was chromatographed on a silica gel column $(80 \mathrm{~cm} \times 5.0 \mathrm{~cm})$ and eluted with $\mathrm{CHCl}_{3} / \mathrm{MeOH} /$ $\mathrm{H}_{2} \mathrm{O}$ (8:2:0.5, lower layer) to afford DSC (2848 mg) (Scheme 1).

\subsubsection{Reagents and Laboratory Equipments}

Brucella broth, bacto agar, horse serum, dimethyl sulfoxide (DMSO), 3-(4,5-dimethylthiazol-2,5-diphenyltetrazolium bromide (MTT), sodium bicarbonate, positive control including ascorbic acid, hydrotalcite, ampicillin and cimetidine were obtained from Sigma (Sigma-Aldrich Inc., MO, USA). The cell culture medium and reagents, including RPMI 1640, fetal bovine serum (FBS), penicil- 


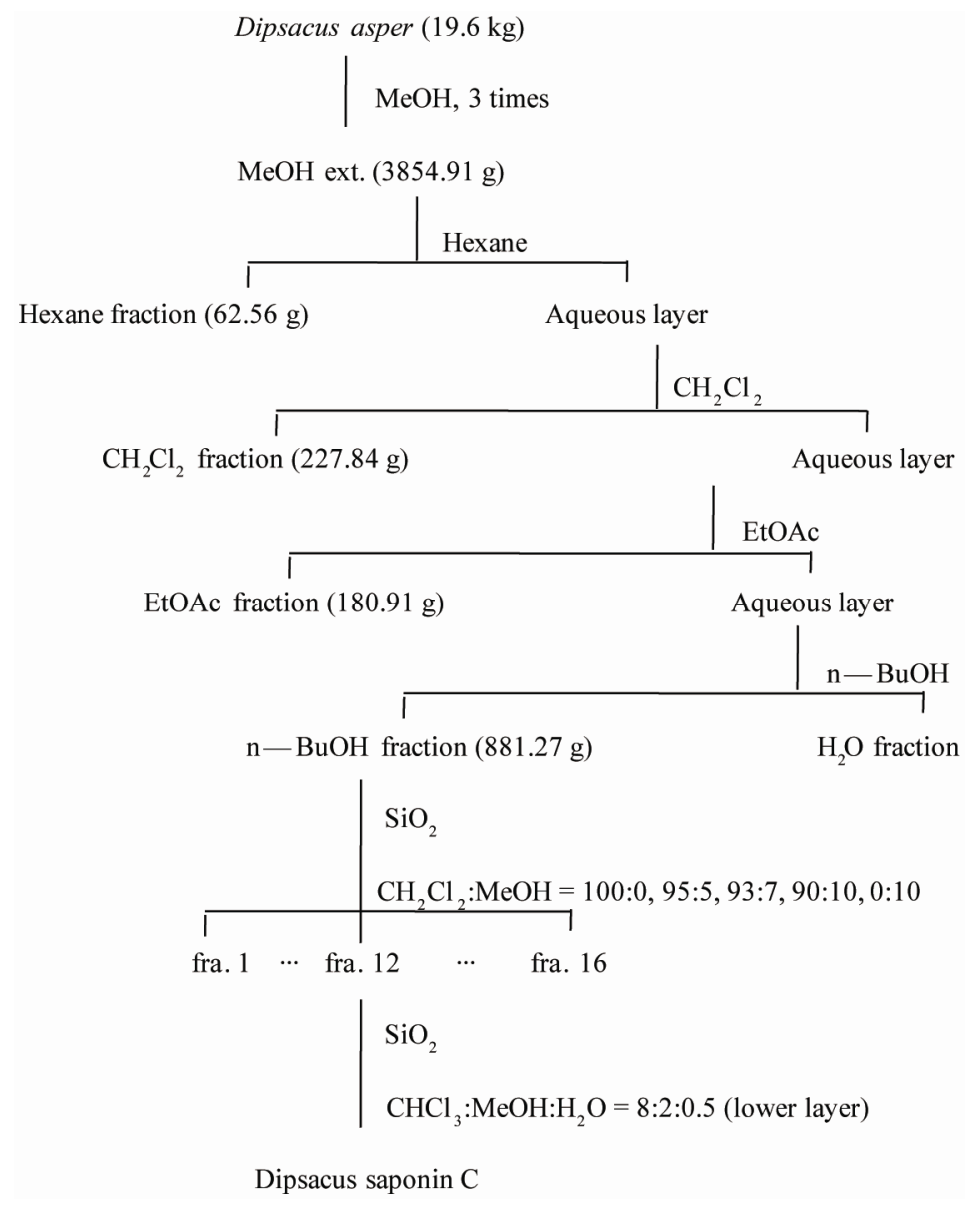

Scheme 1. Extraction, fractionation, and isolation of Dipsacusasper.

lin/streptomycin, and trypsin-EDTA, were purchased from GIBCO (Invitrogen Inc., NY, USA). The other solvents were purchased from Duksan Pure Chemical Co. Ltd. (Kyunggi-do, Korea). All other reagents were of pharmaceutical or analytical grade.

The equipment included a pH meter (IQ Scientific Instruments, Inc.), clean Bench (Johnsam Co.), $\mathrm{CO}_{2}$ incubator (Forma Scientific), water bath (Vision), inverted microscope (Olympus), autoclave (Duksan Chem. Co.), micropipette (Gilson Co.), centrifuge 5810R (Eppendorf), high-speed centrifuge (Sorvall RT-6000), liquid nitrogen Dewars (CHART MVE), and UV-spectrophotometric plate reader (ASYS UVM340).

\subsubsection{Animals}

Male Sprague-Dawley rats, weighing 170 - 180 g, were purchased from Samtako, Kyunggi-do, Korea, and were acclimatized to standard laboratory conditions $\left(22^{\circ} \mathrm{C} \pm\right.$ $2{ }^{\circ} \mathrm{C}, 55 \% \pm 5 \%$ humidity and $12 \mathrm{~h} \mathrm{light/dark}$ cycle) for 14 days in the animal facility in Duksung Women's University. The experimental procedures for rats were conducted in accordance with the Guidelines of the Care and Use of Laboratory Animals, Duksung Women's
University (2009-03-009). The animals were allowed free access to food (standard pellet diet) and water ad libitum. The entire study was conducted in compliance with the Testing Guidelines for Safety Evaluation of Drugs (Notification No. 1999-61) issued by the Korea Food and Drug Administration, the Good Laboratory Practice Regulations for Non-clinical Laboratory Studies (Notification No. 2000-63) issued by the Korea Food and Drug Administration, and the Principles of Good Laboratory Practice issued by the Organization for Economic Cooperation and Development.

\subsubsection{DPPH Radical-Scavenging Capacity}

DPPH radical-scavenging capacities of the samples were analyzed using the slightly modified method of Lee [18]. $1 \mathrm{~mL}$ of DPPH $(150 \mathrm{mM})$ in methanol was added to 4 $\mathrm{mL}$ of samples $(2.5-120 \mathrm{mg} / \mathrm{mL})$; the mixture was then stirred and left for 30 minutes at room temperature. The absorbance of the resulting solution was measured at 520 $\mathrm{nm}$ in an ELISA. The DPPH scavenging percentage was calculated as follows:

DPPH radical - scavenging capacity $(\%)$

$$
=\left[\left(\mathrm{A}_{0}-\mathrm{A}_{1}\right) / \mathrm{A}_{0}\right] \times 100
$$


where $\mathrm{A}_{0}$ is the absorbance of the control, and $\mathrm{A}_{1}$ is the absorbance in the presence of DSC. The concentration providing $50 \%$ inhibition $\left(\mathrm{IC}_{50}\right)$ was found by using a calibration curve. L-Ascorbic acid was used as a positive control.

\subsubsection{Inhibiting Effect $\boldsymbol{H}$. pylori Colonization}

H. pylori (KCTC No. 12083) was used throughout this study and was obtained from Korean Collection for Type Culture (KCTC). $600-\mu \mathrm{L}$ samples of each concentration were injected into $5.4 \mathrm{~mL}$ of brucella agar medium containing $7 \%$ horse serum in apetri dish. H. pylori at $5 \times$ $10^{5} \mathrm{CFU}$ was seeded in this media and then incubated for 3 days in a $37^{\circ} \mathrm{C}$ incubator (Anaero Pak Campylo: $85 \%$ $\mathrm{N}_{2}, 10 \% \mathrm{CO}_{2}, 5 \% \mathrm{O}_{2}$ ). Ampicillin was used as a positive control.

\subsubsection{Cell Culture for MTT Assay}

SNU638 and AGS gastric cancer cells were obtained from the Korean Cell Line Bank (KCLB, Seoul, Korea). The cells were cultured with RPMI-1640 containing 10\% FBS, penicillin (100 units $/ \mathrm{mL})$, and streptomycin (100 $\mu \mathrm{g} / \mathrm{mL}$ ) in a $5 \% \mathrm{CO}_{2}$ humidified incubator at $37^{\circ} \mathrm{C}$. For the subculture, the SNU638 and AGS cells were rinsed twice with phosphate-buffered saline (PBS, $\mathrm{pH}$ 7.4) to remove all traces of serum (which can inhibit trypsin) and subdivided using $0.05 \%$ trypsin with $0.53 \mathrm{mM}$ EDTA.

\subsubsection{Acid-Neutralizing Capacity}

One gram of sample was added to $100 \mathrm{~mL}$ of $0.1 \mathrm{~N} \mathrm{HCl}$ and then incubated for $1 \mathrm{~h}$ at $37^{\circ} \mathrm{C}$ with shaking. The acid-neutralizingcapacity was determined by titrating with $0.1 \mathrm{~N} \mathrm{NaOH}$ using methyl orange as an indicator. Hydrotalcite was used as a positive control.

\subsubsection{HCl-Ethanol-Induced Gastritis}

Male rats were fasted with free access to water for 24 hprior to the experiment. Each rat was then orally administered $1 \mathrm{~mL}$ of $\mathrm{HCl} \cdot$ ethanol solution $(60 \%$ ethanol in
$150 \mathrm{mM} \mathrm{HCl}$ ). One hour later, the animals were anesthetized with ether, and their stomachs were removed and fixed in $2 \%$ formalin for $30 \mathrm{~min}$. The amount of hemorrhage in the glandular portion was measured by summing the total length $(\mathrm{mM})$ of each lesion and expressed as a lesion index. The test substance was given orally $30 \mathrm{~min}$ before the administration of $\mathrm{HCl} \cdot$ ethanol solution [19].

\subsubsection{Gastric Secretion}

Male rats were fasted with free access to water for $24 \mathrm{~h}$, after which they underwent pyloric ligation [20]. They were then immediately administered dipsacussaponin $\mathrm{C}$ or cimetidine intraduodenally. Four hours after the pyloric ligation, the animals were sacrificed and the contents of their stomachs were collected and centrifuged at $500 \times$ $\mathrm{g}$ for $10 \mathrm{~min}$ [21]. The total gastric juice volume and $\mathrm{pH}$ were measured, and the acid output $(\mathrm{mEq} / 4 \mathrm{hrs})$ was determined by titration of the gastric juice with $0.1 \mathrm{~N}$ $\mathrm{NaOH}$ using phenol red as an indicator.

\subsubsection{Indomethacin-Induced Gastric Ulcer}

Indomethacin-induced gastric ulcersamples were analyzed using the slightly modified method of Kasuya [22]. The rats were fasted for $24 \mathrm{~h}$ before the experiment with free access to water and the samples were then orally administered. Thirty minutes later, indomethacin in 50 $\mathrm{mM}$ sodium bicarbonate solution $(35 \mathrm{mg} / \mathrm{kg})$ was given by subcutaneous injection. $7 \mathrm{~h}$ later, the animals were anesthetized with ether, and their stomachs were removed and fixed in $2 \%$ formalin for $30 \mathrm{~min}$. The amount of hemorrhage in the glandular portion was measured by summing a lesion index $\left(\mathrm{mM}^{2}\right)$.

\subsection{Statistical Analysis}

All experiments were carried out at least three times. The data was analyzed using Student's $t$-test. $p$-Values of less than 0.05 were considered significant. When gastric lesions were induced by the various methods, the inhibitory effects of DSC on gastritis and gastric ulcers were determined as the inhibition ratio (\%) as follows:

$$
\text { Inhibition ratio }(\%)=[\text { lesion length }(\text { control })-\text { lesion length }(\text { drug })] / \text { lesion length }(\text { control }) \times 100
$$

\section{Results and Discussion}

\subsection{DPPH Radical-Scavenging Activities}

Oxidants play a significant role in the pathogenesis of a number of disorders such as inflammation, rheumatoid arthritis, asthma, psoriasis and contact dermatitis in which they lead to oxidative stress. Oxidative stress can be defined as an imbalance between cellular production of reactive oxygen species (ROS) and antioxidant defense mechanisms [23]. Antioxidant defense mechanisms against free radical-induced tissue damage may be a new strat- egy for treating $H$. pylori infection and gastritis in humans [24]. In addition to the correlation of chronic gastritis and $H$. pylori infection with increased free-radical production [25], antioxidants such as ascorbic acid may be involved at the early stage of chronic gastritis; its secretion into the stomach is inhibited by infection with $H$. pylori, a major cause of gastritis. Furthermore, invasive cancer is the result of insufficient control of oxidative stress applied to replicating cells over a prolonged period of time [26].

The antioxidant potential of DA extracts and DSC was 
evaluated using the DPPH scavenging capacity. Quantitative determination of DPPH-radical scavenging activities is shown in Table 1. 70\% ethanol extract of DA has free radical scavenging activity $\left(\mathrm{IC}_{50}=51.7 \mathrm{mg} / \mathrm{mL}\right)$. The $\mathrm{IC}_{50}$ of L-ascorbic acid, a positive control, was $<10$ $\mathrm{mg} / \mathrm{mL}$. The DSC and water extract of DA showed low antioxidant activities with $\mathrm{IC}_{50}>160 \mathrm{mg} / \mathrm{mL}$. We investigated DPPH-radical scavenging activities to measure the antioxidant activity of DA at concentrations of $2.5,5$, $10,20,40,80$ and $160 \mu \mathrm{g} / \mathrm{mL}$. From these results, the $70 \%$ ethanol extract of DA has significant free radical scavenging activities and could be good oxidants.

\subsection{Inhibition of $\boldsymbol{H}$. pylori Colonization}

H. pylori is the major causal factor in chronic gastritis and gastric cancer [27]. It is thought to predispose to gastritis, which may progress through metaplastic and dysplastic change to develop into cancer [28]. Infection of the gastric mucosa with H. pylori is strongly associated with chronic gastritis, peptic ulcer disease and gastric cancer. Multivariate logistical regression analysis of data implicating H. pylori as an etiological agent in the development of gastric cancer supports the hypothesis that this organism is an independent risk factor for gastric cancer [29]. The World Health Organization has classified H. pylori as a group I carcinogen, with an attributable risk for gastric cancer of 50\% - 60\% [30]. Antibiotic therapy and multidrug regimens have been used to cure H. pylori infection. However, the emergence of drug resistance requires a new source of drugs, and natural products can offer high potency and selectivity as a result of long evolutionary selection [31].

DSC mildly inhibited the H. pylori colonization at a concentration of $50 \mu \mathrm{M}$ (Table 2). This means DSC might decrease the risk of $H$. pylori-induced gastritis, gastric ulcer and cancer through the inhibition of $H$. pylori survival.

\subsection{Cell Cytotoxicity against Gastric Cancer Cell}

Gastric cancer mortality has declined markedly around the world. In South Australia, the reduction was approximately $40 \%$ over the last 20 years. Possible reasons

Table 1. Free radical scavenging effect of Dipsacus asper and its constituent, Dipsacussaponin $C$.

\begin{tabular}{cc}
\hline Material & $\mathbf{I C}_{\mathbf{5 0}}(\boldsymbol{\mu M})$ \\
\hline Water extract & $>160^{*}$ \\
$70 \%$ Ethanol extract & $51.7^{*}$ \\
Dipsacussaponin C & $>160$ \\
L-Ascorbic acid & $<10^{*}$ \\
\hline
\end{tabular}

${ }^{*} \mu \mathrm{g} / \mathrm{mL}$.
Table 2. H. Pylori colonization inhibitory effect.

\begin{tabular}{lcc}
\hline \multicolumn{1}{c}{ Material } & Dose $(\boldsymbol{\mu M})$ & Colonization \\
\hline Control & - & ++++ \\
Water extract & $10^{*}$ & ++++ \\
& $50^{*}$ & ++++ \\
& $100^{*}$ & ++++ \\
$70 \%$ Ethanol extract & $10^{*}$ & +++ \\
& $50^{*}$ & ++++ \\
& $100^{*}$ & ++++ \\
Dipsacus saponin C & 10 & +++ \\
& 50 & ++ \\
Ampicillin & 100 & ++ \\
& $10^{*}$ & - \\
& $50^{*}$ & - \\
\hline
\end{tabular}

${ }^{*} \mu \mathrm{g} / \mathrm{mL}$; -: none, + : colonies $\left(0-2 \times 10^{4} \mathrm{CFU}\right),++$ : colonies $\left(2-4 \times 10^{4}\right.$ $\mathrm{CFU}),+++$ : colonies $\left(4-6 \times 10^{4} \mathrm{CFU}\right),++++$ : colonies $\left(>6 \times 10^{4} \mathrm{CFU}\right)$.

include: better refrigeration; reduced consumption of salted, smoked, and chemically preserved foods; increased intake of fruit and vegetables; and improved living standards and a greater use of antibiotics, which may have reduced Helicobacter pylori infection [32]. But, gastric cancer remains the fourth most common cancer and the second leading cause of cancer-related death worldwide, probably accounting for about $10 \%$ of newly diagnosed cancers [33]. It is important to treat cancer so we developed a promising anticancer drug with greater pharmacological activity and fewer side effects [34]. Natural compounds with bioactivity potential have meant that several products isolated from plants can serve as sources for new drug leads [35].

Cytotoxicity was assessed by measuring the cell viability of AGS and SNU638 human gastric cancer cell lines. From the results, DSC showed cytotoxicity against AGS gastric cancer cells $\left(\mathrm{IC}_{50}=37.3 \mathrm{mM}\right)$ and SNU638 cells $\left(\mathrm{IC}_{50}=54.6 \mathrm{mM}\right)$ (Figures 2 and $\left.\mathbf{3}\right)$. DSC had dosedependentcytotoxic effects in the gastric cancer cells.

\subsection{Acid-Neutralizing Capacity}

Treatment of gastritis depends on the specific cause, but antacids may be included in the drug regimen. Antacids neutralize existing stomach acid and can provide rapid pain relief. Hydrotalcite is a complex of aluminum hydroxide, magnesium hydroxide, carbonate and $\mathrm{H}_{2} \mathrm{O}$ that neutralizes gastric acid [36]. Adsorption and neutralization by hydrotalcite of all $H$. pylori-secreted proteins may explain the ulcer-healing action of this drug [37]. Hydrotalcite and Rebamipide have been shown to activate the genes encoding EGF, EGF-R and bFGF and its receptors in the gastric mucosa. This activation leads to increased 


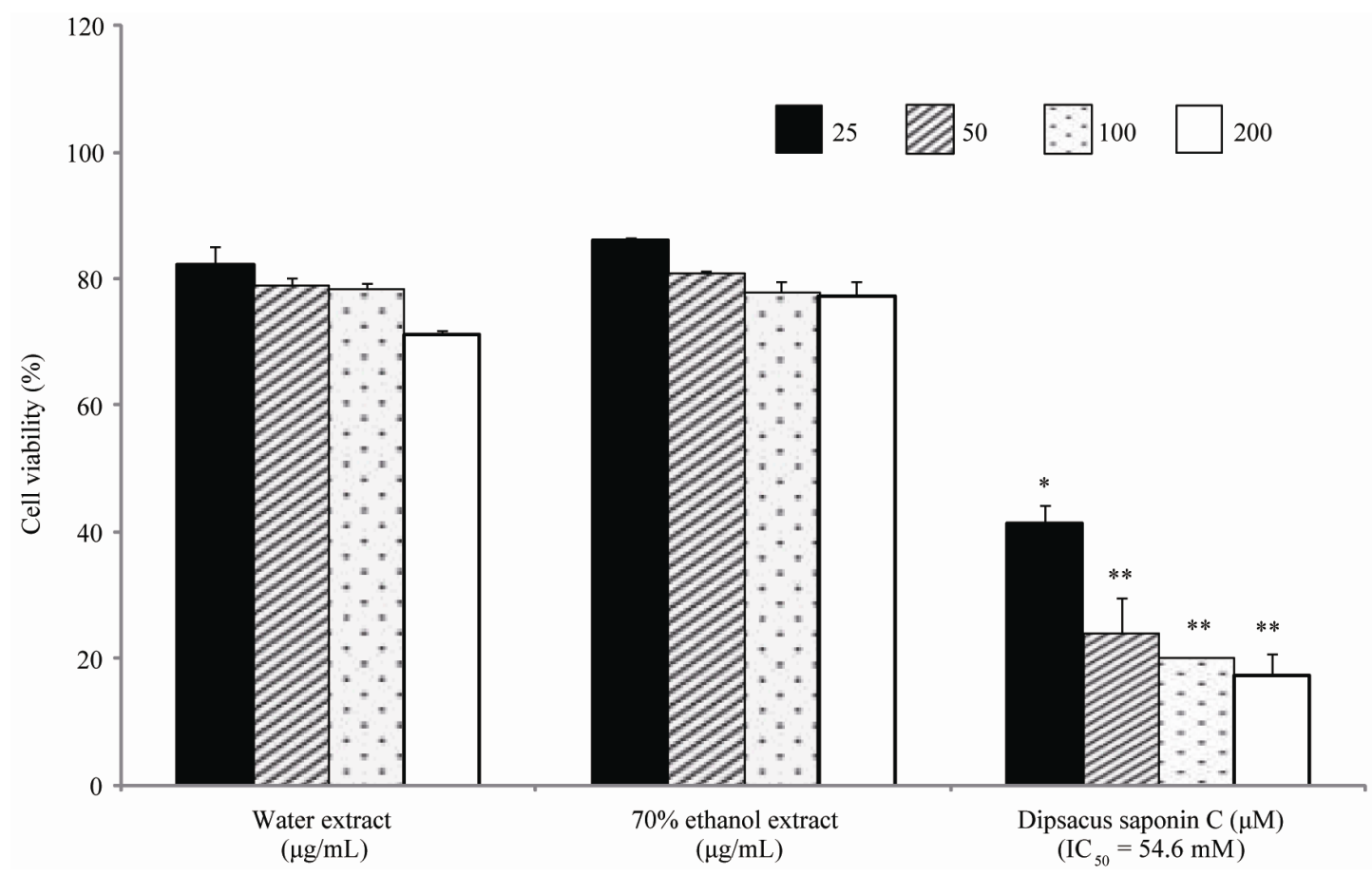

Each value represents the mean \pm S.E. Significantly difference, ${ }^{*} \mathrm{p}<0.05$ compared to the control, ${ }^{* *} \mathrm{p}<0.01$ compared with control.

Figure 2. Cell cytotoxicity against SNU638 cells.

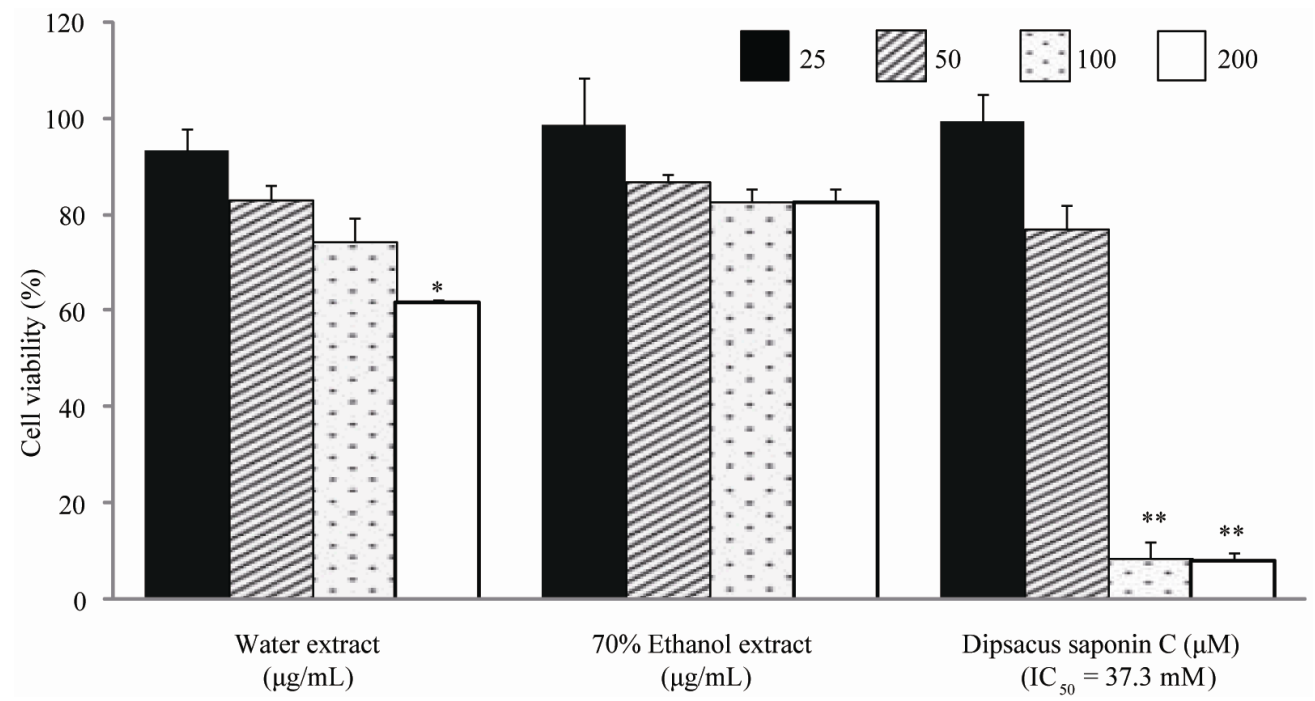

Each value represents the mean \pm S.E. Significantly difference, ${ }^{*} \mathrm{p}<0.05$ compared to the control, ${ }^{* *} \mathrm{p}<0.001$ compared with control.

Figure 3. Cell cytotoxicity against AGS cells.

synthesis of the respective growth factor peptides and their receptors, which, in turn, activate cell proliferation, migration, re-epithelialization and angiogenesis [38]. Therefore, in this study we found that DSC had an acidneutralizing capacity. The acid-neutralizing capacities of the DA extract and DSC were investigated by measuring the volume of $\mathrm{NaOH}$ consumption. The DA water extract and $70 \%$ ethanol extract inhibited $\mathrm{NaOH}$ consumption by
$17.0 \%$ and $18.0 \%$, respectively. In addition, DSC had an acid-neutralizing capacity (15.3\%) compared with the control (Table 3). Although less than that of hydrotalcite, we expected that DSC might be helpful as a nutraceutical due to its gastroprotective effect.

\subsection{HCl$\cdot$ Ethanol-Induced Gastritis}

Oral administration of ethanol interrupts the mucosal 
Table 3. Acid-neutralizing capacity of Dipsacusasper and its constituent, Dipsacussaponin C.

\begin{tabular}{lcc}
\hline \multicolumn{1}{c}{ Material } & $\begin{array}{c}\text { NaOH consumption } \\
\text { volume }(\boldsymbol{\mu L})\end{array}$ & Inhibition (\%) \\
\hline Control & $56.3 \pm 0.58$ & - \\
Water extract & $46.2 \pm 1.25^{*}$ & 15.9 \\
$70 \%$ Ethanol extract & $46.7 \pm 0.58^{*}$ & 15.7 \\
Dipsacussaponin C & $47.7 \pm 0.58^{* *}$ & 15.4 \\
Hydrotalcite & $5.0 \pm 0.00^{*}$ & 91.1 \\
\hline
\end{tabular}

Each value represents the mean \pm S.E. Significantly different, ${ }^{*} \mathrm{p}<0.01$ compared with control, ${ }^{* *} \mathrm{p}<0.001$ compared with control.

defense system, thereby aggravating mucosal damage that might bring about necrosis or apoptosis of gastric mucosal cells [39]. The induction of gastritis resulted in activation of TNF $\alpha$ expression followed by apoptosis in the gastric mucosa. This could lead to an increase in the severity of ulcerative damage in the stomach [40]. Therefore, ethanol facilitates the development of superficial gastritis and chronic atrophic gastritis [41]. And ethanolinduced gastric ulceration in rats and mice is considered to be a reliable tool to study the pathogenesis of acute gastritis [42].

The effects of the water and $70 \%$ ethanol extract from DA and DSC on $\mathrm{HCl} \cdot$ ethanol-induced lesions were investigated, and the results are shown. The lesion index induced by $\mathrm{HCl} \cdot$ ethanol addition was $120.6 \mathrm{mM}$. Compared to this control, treatment with DSC significantly decreased the lesion index to $8.2 \mathrm{mM}(100 \mathrm{mg} / \mathrm{kg})$ and
$15.5 \mathrm{mM}(200 \mathrm{mg} / \mathrm{kg})$. These inhibition rates are $87.1 \%$ $(100 \mathrm{mg} / \mathrm{kg})$ and $93.2 \%(200 \mathrm{mg} / \mathrm{kg})$. Furthermore, these decreases were greater than those seen with hydrotalcite $(100 \mathrm{mg} / \mathrm{kg}), 31.4 \%$ (Figure 4). DSC reduced the potentiality of gastritis induced by ethanol and dangerous environmental factors.

\subsection{Gastric Secretion in Pylorus-Ligated Rats}

Ulcers may arise when there is an imbalance between the aggressive and defensive factors that renders the mucosa susceptible to damage [43]. Pylorus ligation is empirically known to elicit a strong stimulation of gastric secretion during the early stage [44]. The formation of gastric mucosal lesions by necrotizing agents such as $\mathrm{HCl}$ and ethanol is known to be associated with the depression of gastric defensive mechanisms [45]. Therefore, gastric acid suppressors, such as proton pump inhibitors, are used to heal gastric ulcers and peptic ulcer [46]. The effects of DSC on gastric secretion in pylorus-ligated rats were examined, and the results are shown in Figure 5. We measured gastric-juice parameters, gastric volume and $\mathrm{pH}$, after subjecting the rats to pylorus ligation with or without intraduodenal DSC administration. Cimetidine was used as a positive control. Compared to control, treatment with DSC $(200 \mathrm{mg} / \mathrm{kg})$ significantly decreased the total acid output $(0.16 \mathrm{~m} \mathrm{Eq} / 4 \mathrm{hrs})$ to levels comparable to those seen with the same dose $(200 \mathrm{mg} / \mathrm{kg})$ of cimetidine $(0.22 \mathrm{mEq} / 4 \mathrm{hrs})$; DSC also decreased the acid volume from $64 \mathrm{~mL}$ to $2.2 \mathrm{~mL}$ and increased the $\mathrm{pH}$

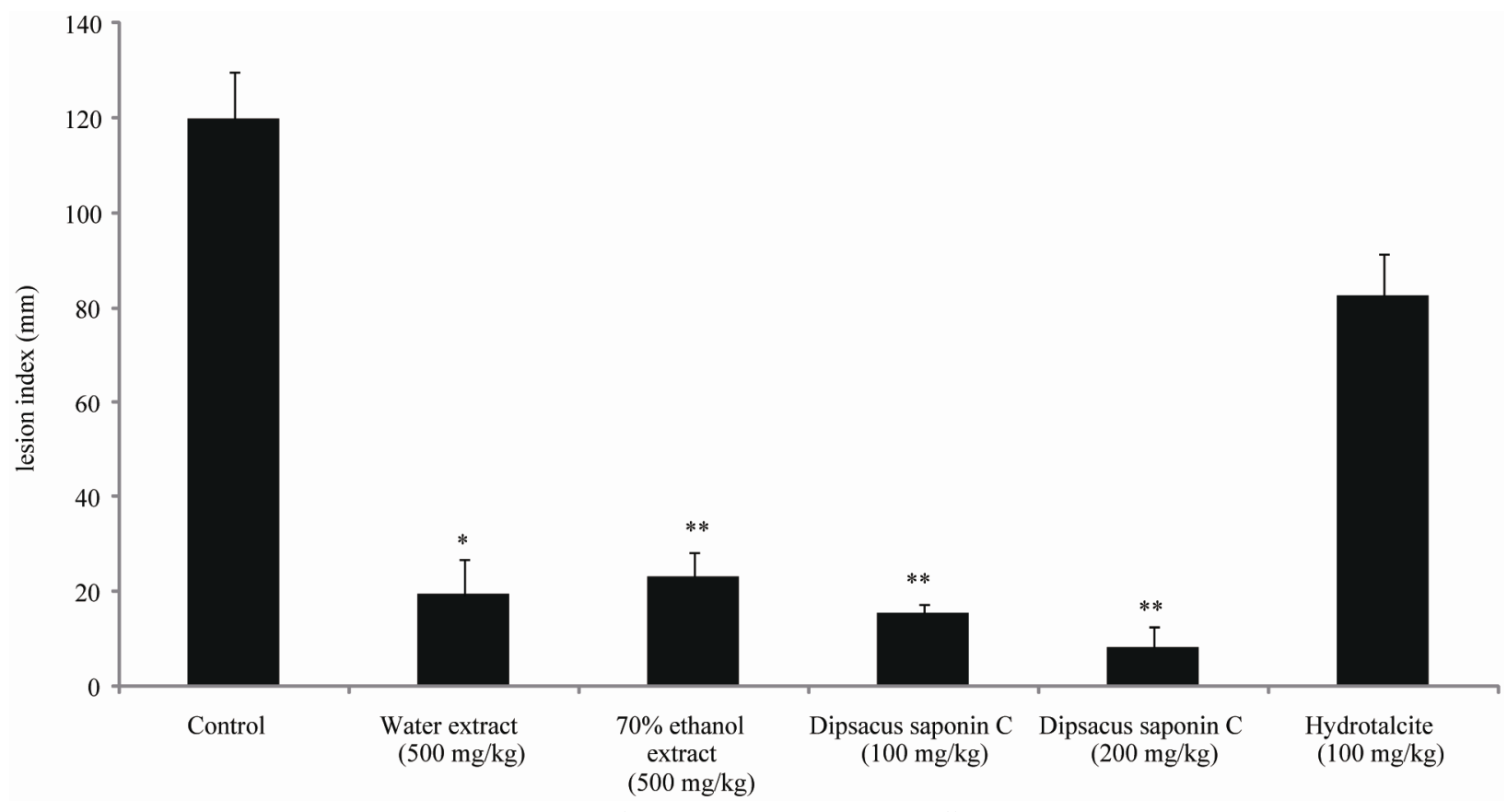

Each value represents the mean \pm S.E. Significantly difference, ${ }^{*} \mathrm{p}<0.01$ compared with control, ${ }^{* *} \mathrm{p}<0.001$ compared with control.

Figure 4. The effect of dipsacussaponin $\mathrm{C}$ on $\mathrm{HCl} \cdot$ ethanol induced gastritis in rats. 
from 1.1 to 2.8. DSC suppressed the gastric secretion by reducing gastric volume and acidity during the early stage.

\subsection{Indomethacin-Induced Gastric Ulcer}

Indomethacin-induced gastric lesions are characterized by significant oxidative injury, reduced mucosal blood flow and reduced secretion of mucus/bicarbonate, mainly due to inhibition of PG secretion [47]. The gastric ulcer production by indomethacin is due to the fact that this compound inhibits the synthesis of cytoprotective prostaglandins by COX-1 and COX-2 in the stomach tissue [48], which in turn inhibits the release of mucus [49].

The effects of DSC on indomethacin-induced gastric lesions in rats were also examined and the results are shown in Figure 6. The lesion index induced by indomethacin was $19.0 \mathrm{mM}$. Compared to this control, treatment with dipsacussaponin $\mathrm{C}$ significantly decreased the

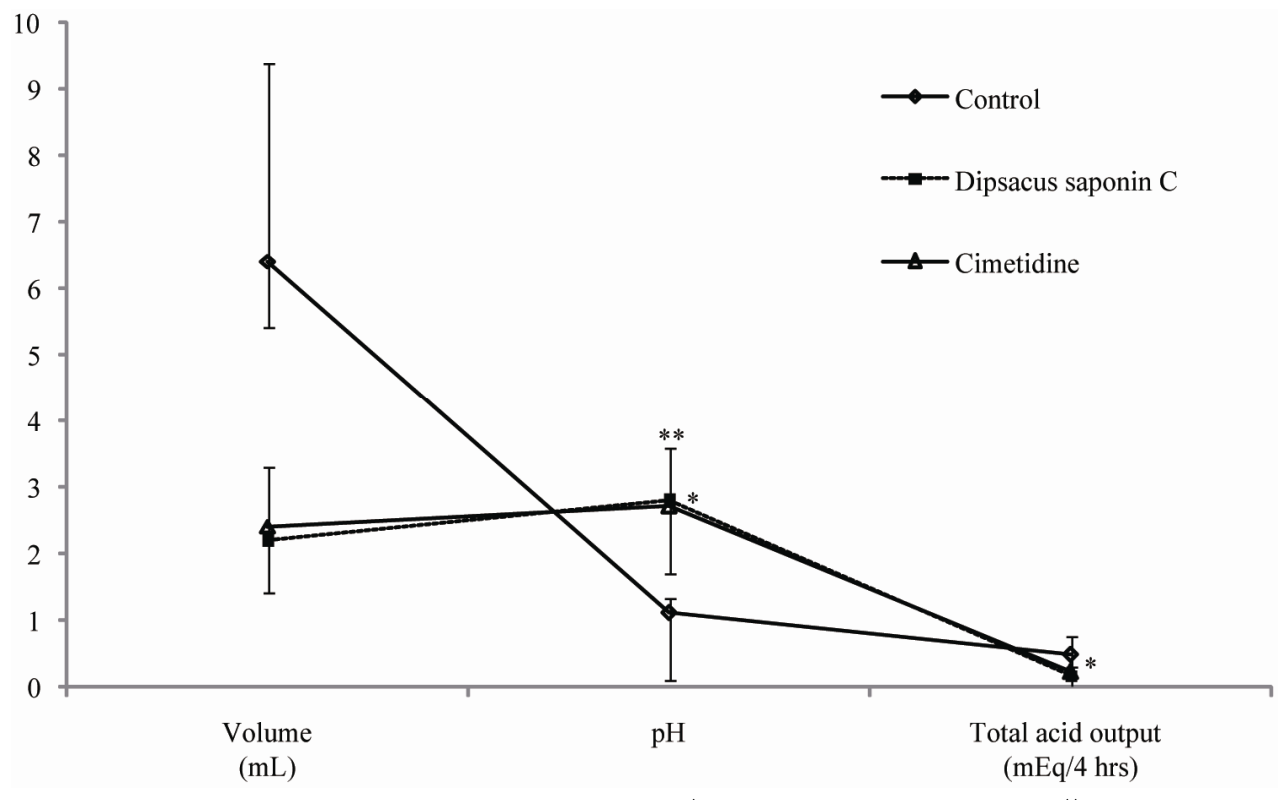

Each value represents the mean \pm S.E. Significantly difference, ${ }^{*} \mathrm{p}<0.05$ compared to the control, ${ }^{* *} \mathrm{p}<0.01$ compared with control.

Figure 5. The effect of dipsacussaponin $\mathrm{C}$ on gastric secretion in pylorus-ligated rats.

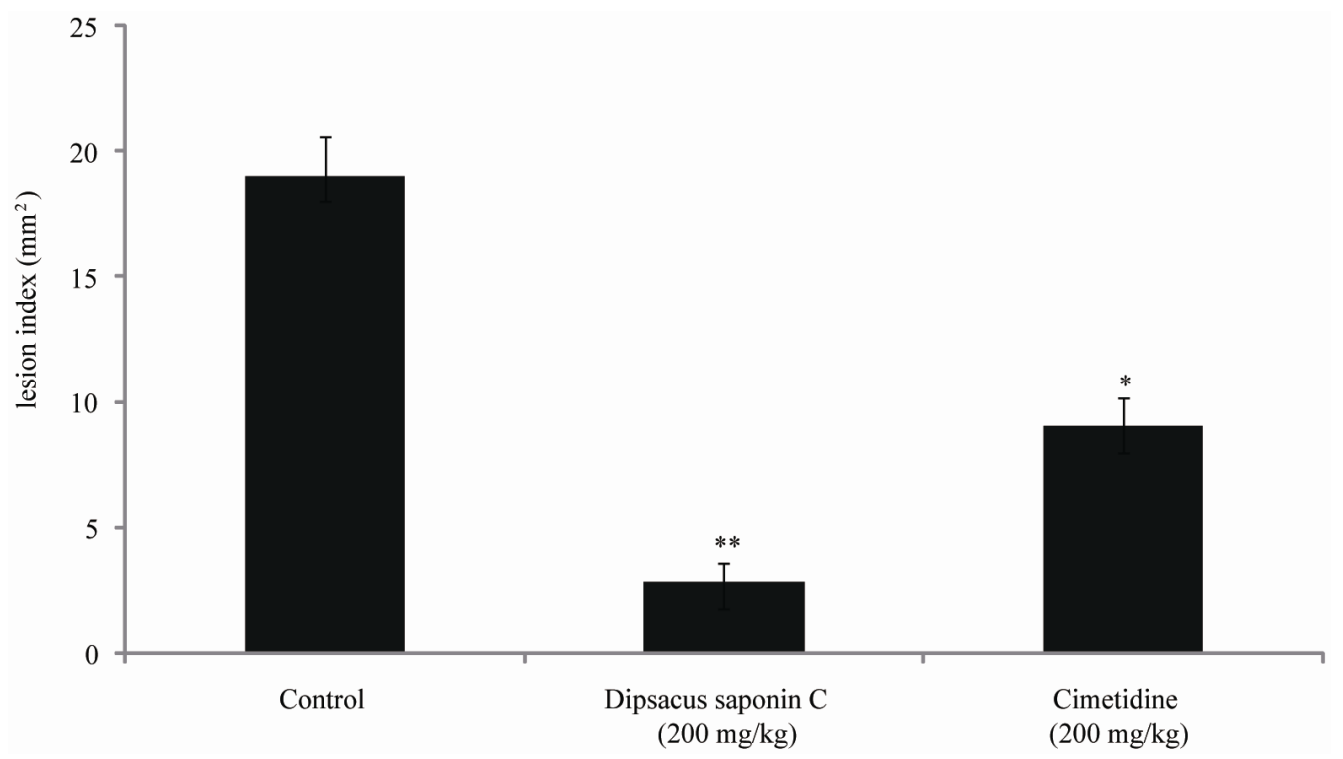

Each value represents the mean \pm S.E. Significantly difference, ${ }^{*} \mathrm{p}<0.01$ compared to the control, ${ }^{* *} \mathrm{p}<0.001$ compared with control.

Figure 6. The effect of dipsacussaponin $\mathrm{C}$ on indomethacin-induced gastric ulcer in rats. 
lesion index to $2.8 \mathrm{mM}(200 \mathrm{mg} / \mathrm{kg})$. The inhibition rate was $87.8 \%(200 \mathrm{mg} / \mathrm{kg})$. This decrease was greater than that seen with cimetidine $(200 \mathrm{mg} / \mathrm{kg}), 9.0 \mathrm{mM}$. DSC reduced the potentiality of gastric ulcer through its cytoprotective effects, and its prostaglandin-synthesizing capacity should be further investigated.

\section{Conclusion}

DSC isolated from DA inhibited the H. pylori growth, reduced gastric lesions and ulcers in rats. From these results, we suggest that DSC from DA could be new potential drug for prevent/reduce gastritis and gastric ulcers.

\section{Acknowledgements}

This study was supported by a grand from the Food \& Drug Administration, Republic of Korea and Priority Research Centers Program through the National Research Foundation of Korea (NFR) funded BY THE Ministry of Education, Science and Technology (2011-0031386).

\section{REFERENCES}

[1] Jiokpyo, "Pharmacognosy," Sungkyunkwan University Press, Seoul, 2009.

[2] T. Namba, "The Encyclopedia of Wakan-Yaku," Traditional Sino-Japanese Medicines with Color Pictures, Hoikusha Publishing Company, Osaka, 1993.

[3] X. Y. Tian, Y. H. Wang, H. Y. Liu, S. S. Yu and W. Shuo, "On the Chemical Constituents of Dipsacusasper," Zhou Fang Pharm Chemical, Vol. 3, No. 55, 2007, pp. 16771681.

[4] Z. J. Zhang, Y. H. Qian, H. T. Hu, J. Yang and G. D. Yang, "The Herbal Medicine Dipsacusasper Wall Extract Reduces the Cognitive Deficits and over Expression of $\beta$-Amyloid Protein Induced by Aluminum Exposure," Life Sciences, Vol. 73, No. 19, 2003, pp. 2443-2454. doi:10.1016/S0024-3205(03)00649-0

[5] T. M. Hung, W. Y. Jin, P. T. Thuong, K. S. Song and K. H. Bae, "Cytotoxic Saponins from the Root of Dipsacusasper Wall," Archives of Pharmacal Research, Vol. 28, No. 9, 2005, pp. 1053-1056. doi:10.1007/BF02977401

[6] C. Li, Z. Liu, J. Tian, G. Li, W. Jiang, G. Zhang, F. Chen, P. Lin and Z. Ye, "Protective Roles of Asperosaponin VI, a Triterpenesaponin Isolated from Dipsacusasper Wall on Acute Myocardial Infarction in Rats," European Journal of Pharmacology, Vol. 627, No. 1, 2010, pp. 235-241. doi:10.1016/j.ejphar.2009.11.004

[7] S. I. Jeong, B. Zhou, J. B. Bae, N. S. Kim, S. G. Kim, J. Kwon, D. K. Kim, T. Y. Shin, H. Jeon, J. P. Lim, H. J. Kim, H. K. Kim and C. H. Oh, "Apoptosis-Inducing Effect of Akebiasaponin D from the Roots of Dipsacusaasper Wall in U937 Cells," Archives of Pharmacal Research, Vol. 31, No. 11, 2008, pp. 1399-1404. doi:10.1007/s12272-001-2123-0

[8] T. M. Hung, M. K. Na, P. T. Thuong, N. D. Su, D. E. Sok,
K. S. Song, Y. H. Seong and K. H. Bae, "Antioxidant Activity of Caffeoylquinic Acid Derivatives from the Roots of Dipsacusasper Wall," Journal of Ethnopharmacology, Vol. 108, No. 2, 2006, pp. 188-192. doi:10.1016/j.jep.2006.04.029

[9] H. Suh, D. Song, S. Huh, K. Son and Y. Kim, "Antinociceptive Mechanisms of Dipsacussaponin C Administered Intrathecally in Mice," Journal of Ethnopharmacology, Vol. 71, No. 1-2, 2000, pp. 211-218. doi:10.1016/S0378-8741(99)00204-4

[10] X. Liu, Z. Chen, N. Mao and Y. Xie, "The Protective of Hydrogen on Stress-Induced Gastric Ulceration," International Immunopharmacology, Vol. 13, No. 2, 2012, pp. 197-203. doi:10.1016/j.intimp.2012.04.004

[11] J. Nash, L. Lambert and M. Deakin, "Histamine H2-Receptor Antagonists in Peptic Ulcer Disease: Evidence for a Prophylacticuse," Drugs, Vol. 47, No. 3, 1994, pp. 862871. doi:10.2165/00003495-199447060-00002

[12] S. K. Bandyopadhyay, S. C. Pakrashi and A. Pakrashi, "The Role of Antioxidant Activity of Phyllanthusemblica Fruits on Prevention from Indomethacin Induced Gastric Ulcer," Journal of Ethnopharmacology, Vol. 70, No. 2, 2000, pp. 171-176. doi:10.1016/S0378-8741(99)00146-4

[13] P. Correa, M. B. Piazuelo, A. Source and W. Potter, "Helicobacter Pylori Infection and Gastric Adenocarcinoma," US Gastroenterology \& Hepatology Reviews, Vol. 7, No. 1, 2011, pp. 59-64.

[14] E. J. Kuipers, "Helicobacter Pylori and the Risk and Management of Associated Diseases: Gastritis, Ulcer Disease, Atrophic Gastritis and Gastric Cancer," Alimentary Pharmacology \& Therapeutics, Vol. 11, No. 1, 1997, pp. 77-88. doi:10.1046/j.1365-2036.11.s1.5.x

[15] P. Sipponen and H. Hyvärinen, "Role of Helicobacter pylori in the Pathogenesis of Gastritis, Peptic Ulcer and Gastric Cancer," Scandinavian Journal of Gastroenterology, Vol. 28, No. 196, 1993, pp. 3-6. doi: 10.3109/00365529309098333

[16] L. A. Ries, M. P. Eisner, C. L. Kosary, B. F. Hankey, B. A. Miller, L. Clegg and B. K. Edwards, "SEER Cancer Statistics Review," National Cancer Institute, Bethesda, 2000, pp. 1973-1999.

[17] K. Y. Jung, K. H. Son and J. Chu, "Triterpenoids from the Roots of Dipsacusasper," Archives of Pharmacal Research, Vol. 16, No. 1, 1993, pp. 32-35. doi:10.1007/BF02974125

[18] E. J. Lee, K. S. Kim, H. Y. Jung, D. H. Kim and H. D. Jang, "Antioxidant Activities of Garlic (Allium sativum L.) with Growing Districts," Food Science and Biotechnology, Vol. 14, No. 1, 2005, pp. 123-130.

[19] T. Mizui and M. Dodeuchi, "Effect of Polyamines on Acidified Ethanol-Induced Gastric Lesion in Rats," Journal of Pharmacology, Vol. 33, No. 5, 1983, pp. 939-945.

[20] H. Shay, S. A. Komarov, S. S. Fels and D. Meranze, "Asimple Method for the Uniform Production of Gastric Ulceration in the Rat," Gastroenterology, Vol. 4, No. 3, 1945, pp. 43-61.

[21] H. S. Park and K. S. Yang, "Effects of Dipsacusasper on Free Radical Scavenging and Low Density Lipoprotein 
Oxidation," Yakhak Hoechi, Vol. 20, No. 1, 2006, pp. 4751.

[22] Y. Kasuya, T. Urushidani and S Okabe, "Effects of Various Drugs and Vagotomy on Indomethacin-Induced Gastric Ulcers in the Rat," Journal of Pharmacology, Vol. 29, No. 4, 1979, pp. 670-673.

[23] A. A. Geronikaki and A. M. Gavalas, "Antioxidants and Anti-Inflammatory Diseases: Synthetic and Natural Antioxidants with Anti-Inflammatory Activity," Combinatorial Chemistry \& High Throughput Screening, Vol. 9, No. 18, 2006, pp. 425-442. doi:10.2174/138620706777698481

[24] P. Correaa, T. H. Elizabeth, J. C. Fontham, L. E. B. Bravo, B. Ruiz, G. Zarama, J. L. Realpe, G. T. Malcom, D. Li, W. D. Johnson and R. Mera, "Chemoprevention of Gastric Dysplasia: Randomized Trial of Antioxidant Supplements and Anti-Helicobacter Pylori," Therapy Oxford Journals Medicine, Vol. 92, No. 23, 2000, pp. 1881-1888.

[25] F. Farinati, D. Li. Gianni, C. Romilda, M, Alfio, P. Mario, R. Massimo, D. M. Francesco and N. Remo, "Gastric Antioxidant, Nitrites, and Mucosal Lipoperoxidation in Chronic Gastritis and Helicobacter pylori Infection," Journal of Clinical Gastroenterology, Vol. 22, No. 4, 1996, pp. 275281. doi:10.1097/00004836-199606000-00007

[26] P. Correaa, "The Role of Antioxidants in Gastric Carcinogenesis," Critical Reviews in Food Science and $\mathrm{Nu}$ trition, Vol. 35, No. 1-2, 1995, pp. 59-64. doi:10.1080/10408399509527687

[27] J. Houghton, J. G. Fox and T. C. Wang, "Gastric Cancer: Laboratory Bench to Clinic," Journal of Gastroenterology and Hepatology, Vol. 17, No. 4, 2002, pp. 495-502. doi:10.1046/j.1440-1746.2002.02770.x

[28] S. Kono, "Supercourse. Gastric Cancer Epidemiology," Kyushu University School of Medicine, Fukuoka, 2001.

[29] L. E. Hansson, L. Engstrand, O. Nyren, D. J. Evans, A. Lindgren, R. Bergstrom, B. Andersson, L. Athlin, O. Bendtsen and P. Tracz, "Helicobacter Pylori Infection: Independent Risk Indicator of Gastric Adenocarcinoma," Gastro, Vol. 105, No. 4, 1993, pp. 1098-1103.

[30] D. T. Smoot, T. B. Elliott, H. W. Verspaget, D. Jones, C. R. Allen, K. G. Vernon, T. Bremner, L. C. R. Kidd, K. S. Kim, J. D. Groupman and H. Ashktorab, "Influence of Helicobacter Pylori on Reactive Oxygen-Induced Gastric Epithelialcell Injury,” Carcinogenesis, Vol. 21, No. 11, 2000, pp. 2091-2095. doi:10.1093/carcin/21.11.2091

[31] P. Ian and E. A. Anderson, "The Renaissance of Natural Products as Drug Candidates," Science, Vol. 2, No. 5747, 2005, pp. 451-453.

[32] D. M. Roder, "The Epidemiology of Gastric Cancer Clinical and Translational Oncology," Gastric Cancer, Vol. 9, No. 12, 2002, pp. 767-776.

[33] D. M. Parkin, F. I. Bray and S. S. Devesa, "Cancer Burden in the Year. The Global Picture," European Journal of Cancer, Vol. 37, No. 8, 2001, pp. 4-66. doi:10.1016/S0959-8049(01)00267-2

[34] M. Gordaliza, "Natural Products as Leads to Anticancer Drugs," Life Sciences, Vol. 78, No. 5, 2005, pp. 431-441.

[35] J. M. Balunas and D. Kinghorn, "Drug Discovery from
Medicinal Plants," Natureceuticals, Vol. 78, No. 5, 2005, pp. 431-441.

[36] B. P. Yu, J. Sun, M. Q. Li, H. S. Luo and J. P. Yu, "Preventive Effect of Hydrotalcite on Gastric Mucosal Injury in Rats Induced by Taurocholate," World Journal of Gastroenterology, Vol. 3, No. 9, 2003, pp. 1427-1430.

[37] A. Tarnawski, R. Pai and R. Itani, "The Antacid Talcid Adsorbs and Neutralizes All Proteins Secreted by H. pylori IncludingVacACytotoxin: A New Mechanism for Its Ulcer-Healing Action?" Digestion, Vol. 60, No. 5, 1999, pp. 449-455. doi:10.1159/000007690

[38] A. Tarnawski, T. Arakawa and K. Kobayashi, "Rebamipide Treatment Activates Epidermal Growth Factor and Its Receptor Expression in Normal and Ulcerated Gastric Mucosa. The Key Mechanisms for Its Ulcer Healing Action?" Digestive Disease and Sciences, Vol. 43, No. 9, 1998, pp. 90-98

[39] J. S. Lee, T. Y. Oh, Y. K. Kim, J. H. Baik and S. So, "Protective Effects of Green Tea Polyphenol Extracts against Ethanol-Induced Gastric Mucosal Damages in Rats: Stress-Responsive Transcription Factors and MAP Kinases as Potential Targets," Mutation Research, Vol. 579, No. 1-2, 2005, pp. 214-224. doi:10.1016/j.mrfmmm.2005.03.027

[40] S. L. Edgar, C. Liu and H. Cho, "Relationship between Ethanol-Induced Gastritis and Gastric Ulcer Formation in Rats," Digestion, Vol. 62, No. 4, 2000, pp. 232-239. doi:10.1159/000007821

[41] L. Bujanda, "The Effects of Alcohol Consumption upon the Gastrointestinal Tract," The American Journal of Gastroenterology, Vol. 95, No. 12, 2000, pp. 3374-3382. doi:10.1111/i.1572-0241.2000.03347.x

[42] E. R. Rios, N. F. Rocha, E. T. Venâncio, B. A. Moura, M. L. Feitosa, G. S. Cerqueira, P. M. Soares, D. J. Woods, F. C. de Sousa, L. K. Leal and M. M. Fonteles, "Mechanisms Involved in the Gastroprotective Activity of Esculin on Acute Gastric Lesions in Mice," Chemico-Biological Interactions, Vol. 188, No. 1, 2010, pp. 246-254. doi:10.1016/i.cbi.2010.07.020

[43] K. R. Mcquaid and J. I. Isenberg, "Medical Therapy of Peptic Ulcer Disease," The Surgical Clinic of North America, Vol. 72, No. 2, 1992, pp. 285-316.

[44] S. Okabe, K. Takeuchi, K. Nakamura and K. Takagi, "Pathogenesis of Gastric Lesions Induced by Aspirin in the Pylorus-Lygated Rat," The Japanese Journal of Pharmacology, Vol. 24, No. 3, 1974, pp. 363-371. doi:10.1254/jip. 24.363

[45] M. Kinoshita, T. Noto and H. Tamaki, "Effect of a Combination of Ecabet Sodium and Cimetidine on Experimentally Induced Gastric Lesions and Gastric Mucosal Resistance to Ulcerogenic Agents in Rats," Biological Pharmaceutical Bulletin, Vol. 18, No. 2, 1995, pp. 223226. doi:10.1248/bpb.18.223

[46] C. A. M. Stedman1 and M. L. Barclay1, "Comparison of the Pharmacokinetics, Acid Suppression and Efficacy of Proton Pump Inhibitors," Alimentary Pharmacology \& Therapeutics, Vol. 14, No. 8, 2000, pp. 963-978. doi:10.1046/j.1365-2036.2000.00788.x

[47] Ch. V. Rao, S. K. Ojha, K. Radhakrishnan, R. Govinda- 
rajen, S. Rastogi, S. Mehrotra and P. Pushpangadan, "Antiulcer Activity of Utleriasalicifolia Rhizome Extract," Journal of Ethnopharmacology, Vol. 91, No. 2-3, 2004, pp. 243-249. doi:10.1016/i.jep.2003.12.020

[48] G. E. De Souza, R. A. Cardoso, M. C. Melo, A. S. Fabricio, V. M. Silva, M. Lora and A. J. Fernandes, "A Comparative Study of the Antipyretic Effects Of Indomethacin and Dipyrone in Rats," Inflammation Research, Vol. 51, No. 1, 2002, pp. 24-32. doi:10.1007/PL00000278

[49] N. Hudson, A. B. Hawthorne, A. T. Cole, P. D. Jones and C. J. Howley, "Mechanism of Gastric and Duodenal Damage and Protection," Hepatogastroenterology, Vol. 39, No. 1, 1992, pp. 31-36. 